\title{
Factor Analysis of Enterprise Internet+ Impetus Based on
}

\section{System Dynamics}

\author{
Haiwang $\mathrm{Cao}^{1}$, Chaogai Xue ${ }^{2}$ and Xinfeng Wang ${ }^{2}$ \\ ${ }^{1}$ Department of Electronic and Communication Engineering, Zhengzhou Institute of Aeronautical Industry Management, \\ Zhengzhou, Henan, 450015, China \\ ${ }^{2}$ School of Management Engineering, Zhengzhou University, Zhengzhou, Henan, 450001, China
}

\begin{abstract}
Internet + plays an important role in the transition and upgrading of enterprises in this era. To promote enterprise Internet + implementation, this paper studies the influencing factors in enterprise Internet + impetus. First, based on system dynamics, the influencing factors of enterprise Internet + impetus are analyzed as well as their relationships. Then, a system dynamics model is established and Vensim PLE is utilized to simulate the model. Finally, some suggestions about the Internet+ implementation are given. The simulation results show that technological environment, government policy and information asymmetry all have different influence on the enterprise Internet+ impetus and different strategies can be taken to change their influence. This study is helpful for enterprises to understand the Internet + impetus mechanism thus promote Internet+ implementation.
\end{abstract}

\section{Introduction}

With the government report of China in 2015 [1], Internet + is proposed for the first time and become a national strategy of China. Under the background of national network strategy, cloud computing, big data, mobile internet, networking and other technologies provide a good technical support for enterprise Internet + implementation. Internet + pushes enterprises to fuse into the internet, and realizes integration of online and offline resource, as well as different enterprises and different industries [2]. However, facing new situation, enterprises confuse about what influences Internet+ implementation and how to promote Internet + impetus. To this end, this study analyzes the factors influencing enterprise Internet + impetus and their mutual relations, and tries to find the casual relationships of enterprise Internet + impetus so as to provide references for the implementation of enterprise Internet + .

In recent years, there are studies about Internet + in different aspects, which can be briefed as follows: (1) Concepts of Internet + . These studies are mainly about the concepts, structure and connotation of Internet + . For example, Ning[3] studies the connotation, background and content of Internet + . You [4] propose that Internet + is more than informatization, and its essence is the online data. As for traditional enterprises, it is a process of transformation and upgrading of traditional industries. (2)Technologies of Internet+. These studies are mainly about the technologies in Internet + , such as cloud computing, big data, mobile Internet, networking and other technologies [5,6]. Sun et.al. [5] Discuss the general rules of the development of energy and information infrastructure. (3) Applications of Internet + in different fields. These studies are mainly about the applications of Internet+ in different fields. For example, Zhao [7] discusses material 
information system railway engineering project under the background of Internet + . Though the studies on Internet+ provide good foundation, there is few study about factors influencing enterprise Internet+ impetus.

System dynamics was proposed by professor Forrster, W. Jay at the Massachusetts Institute of Technology, and is mainly used for the studies of relationships between complex system structure, functions and dynamic behaviour. Through dynamic simulation experiments, the system dynamic behaviour and trend can be studied under different input of factors. As to the studies of complex nonlinear systems, it has incomparable advantages, thus it has been widely used in almost all fields of society, economy, management, resource environment and so on [8-10]. However, there is no such relative reference in the factor analysis of enterprise Internet + impetus.

From relevant literature, few scholars have studied the factors influencing enterprise Internet + impetus based on system dynamics. Therefore, this paper further explores the relationships among the factors influencing Internet + impetus, and tries to build system dynamic model of enterprise Internet+ impetus so as to provide decision making support for enterprises and relative agencies.

\section{Factor analysis of enterprise Internet+ impetus}

Based on system dynamic complexity science and feedback control theory, system dynamics is mainly used to study the dynamic behaviour of complex system to understand and solve system phenomena [9]. The implementation of Internet+ is a complex process with non-linear dynamic complex features. Therefore, system dynamics is suitable to identify the impetus elements of enterprise Internet + implementation and build a system flow diagram or make feedback loop analysis. Based on previous studies, this paper divides the factors of enterprise Internet+ implementation into external and internal factors.

\subsection{External Factors}

The external factors of enterprise Internet + impetus can be divided into the following ways:

(1)Government influence. From government work report in 2015 to Internet+ manufacturing in 2016, the era of enterprise Internet + has come. From the national level, increasing policy support in tax, finance and land enable enterprises to implement Internet+. With the rapid development of internet and the rapid growth of information, relevant laws and regulations also need to regulate the network market, maintain information security, and solve the conflict between online and offline, so as to pave the way for Internet + smoothly. Meanwhile, the introduction of technology, professional guidance, and coordination between online and offline are all things can be done by government.

(2)Competitor influence. When enterprises implement Internet+, they are facing more competitors. The Internet+ impetus of competitors affects their market competitiveness, thus influences the implementation of enterprises.

(3) Internet + consciousness. In the era of innovation 2.0, the new ecosystem based on internet has updated as well as technologies. The essence of enterprise Internet + is the fusion of internet and enterprises through the information communication technology. Procurement of raw materials, production, warehousing and sales et. al. need support of internet. Communication cannot do without internet, as well as internal management and daily information. Therefore, it is necessary for big data and cloud system to tap the potential resources and improve collaborative processing capabilities. The information communication technology has promoted the enterprise informatization, and enhanced the enterprise's Internet + consciousness. To gain competition capacity, enterprises continue to improve consciousness of Internet + , and this is also an important external factor of Internet + impetus.

\subsection{Internal Factors}

The internal factors of enterprise Internet + impetus include the following aspects: 
(1)Management mode. The rapid and timely information is the key to Internet + era. Traditional linear functional organization structure cannot adapt to the information age, and the enterprise management mode is very important to Internet+ implementation.

(2)Information asymmetry. In the enterprise and customer communication, the asymmetry of information will lead to poor communication of internal enterprises as well as the communication with customers, thus results into the decline in market response ability. Thus, the degree of information asymmetry is one of the key internal factors influencing the enterprise Internet + impetus.

(3)Innovation capacity of employee. In Internet+ era, the personnel training and management are very important for enterprises. If the employee have high level of innovation capacity, then they may have more Internet+ consciousness, thus affect the entire enterprise Internet+ development progress and implementation. Technical upgrading needs talents to operate the application, and new management mode also needs innovative personnel to coordinate. The cultivation of innovative and divergent thinking is an important power for Internet + implementation.

(4)Innovation on product development. Product customization and intelligence are two new ways to improve the competitiveness of products in Internet+ era. Product research and development need data mining on customs, and then products can be promoted to customized development. In Internet+ environment, enterprises in the technological innovation has also increased the intelligent degree of products. Therefore, the enterprises' innovation on product development is an important factor influencing enterprise Internet+ implementation.

(5)Innovation on marketing. The innovation of marketing improves the competitiveness of products in Internet + era. Diversification of marketing channels gave birth to the diversification of interactive channels, and solve the problem of poor customer communication in a certain degree. Thus, the enterprises' effort on market innovation determines the impetus of Internet+.

As discussed above, we have the following factors influencing the impetus of enterprise Internet + , as shown in Table1.

Table 1. Influencing factors of enterprise Internet+ impetus.

\begin{tabular}{|c|c|c|c|}
\hline \multicolumn{2}{|c|}{ External factors } & \multicolumn{2}{|c|}{ Internal factors } \\
\hline \multirow{2}{*}{$\begin{array}{l}\text { Government } \\
\text { strategies }\end{array}$} & National strategies & \multirow{2}{*}{\multicolumn{2}{|c|}{ Management mode innovation }} \\
\hline & Regional strategies & & \\
\hline \multirow{2}{*}{$\begin{array}{l}\text { Technological } \\
\text { environment }\end{array}$} & $\begin{array}{l}\text { Development of } \\
\text { communication } \\
\text { technologies }\end{array}$ & \multirow{2}{*}{$\begin{array}{l}\text { Information } \\
\text { asymmetry }\end{array}$} & $\begin{array}{l}\text { Poor communication in } \\
\text { internal enterprise }\end{array}$ \\
\hline & $\begin{array}{l}\text { Security of network } \\
\text { technologies }\end{array}$ & & $\begin{array}{l}\text { Poor communication with } \\
\text { customs }\end{array}$ \\
\hline \multirow{6}{*}{ Competitor } & Offline enterprises & \multirow{2}{*}{$\begin{array}{l}\text { Innovation capacity of } \\
\text { employee }\end{array}$} & $\begin{array}{c}\text { entrepreneur Internet }+ \\
\text { consciousness }\end{array}$ \\
\hline & Substitute enterprises & & $\begin{array}{l}\text { Employee Internet }+ \\
\text { consciousness }\end{array}$ \\
\hline & \multirow{4}{*}{ Online enterprises } & \multirow{2}{*}{$\begin{array}{l}\text { Innovation on product } \\
\text { development }\end{array}$} & $\begin{array}{c}\text { Requirement of product } \\
\text { design }\end{array}$ \\
\hline & & & Requirement of product $\mathrm{R} \& \mathrm{D}$ \\
\hline & & \multirow{2}{*}{$\begin{array}{l}\text { Innovation on } \\
\text { marketing }\end{array}$} & Marketing strategies \\
\hline & & & Marketing channels \\
\hline
\end{tabular}

\section{Internet+ impetus model based on system dynamics}

\subsection{Causal loop diagram of Internet+ impetus model}

According to the factor analysis, both internal and external factors influence the enterprise Internet+ impetus. The external impetus of enterprise Internet+ is mainly government policies (including national policies and regional policies), the existing information and communication technology environment, and enterprise competition; internal impetus is mainly composed of business management, personnel innovation capacity, product innovation, marketing innovation etc. 
The impetus mechanism of enterprise Internet + is a combination of internal and external dynamic mechanism. Various elements of impetus compose causal relationships. In order to study the impetus mechanism of enterprise Internet + , it is necessary to use the viewpoints of system theory, and view enterprise Internet+ process as a dynamic, complex and open system, and there are dynamic relationships between elements. Based on above analysis, the causal relationship diagram of Internet+ impetus is shown in Figure 1.

There are several feedback loops in Figure 1, and entrepreneur Internet + consciousness is taken as an example shown as follows:

entrepreneur Internet + consciousness $\rightarrow$ management mode innovation $\rightarrow$ application of communication technology $\rightarrow$ employee $\quad$ skills $\rightarrow$ marketing innovation $\rightarrow$ product $\quad$ competition $\rightarrow$ market $\quad$ competition $\rightarrow$ entrepreneur Internet + consciousness.

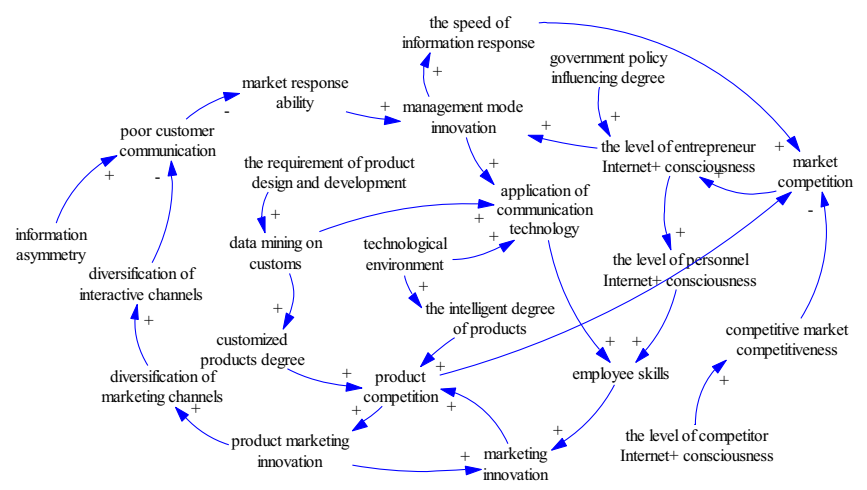

Fig. 1. Causal relationship diagram of Internet + impetus.

\subsection{Stock and flow diagram of Internet+ impetus model}

The interaction of various factors in causality diagram of system dynamics model is actually a mathematical relation, and stock and flow diagram is specific to this mathematical relationship, shown in Figure 2. Based on the previous research and field investigation data of enterprise Internet + , the main parameters are set as follows:

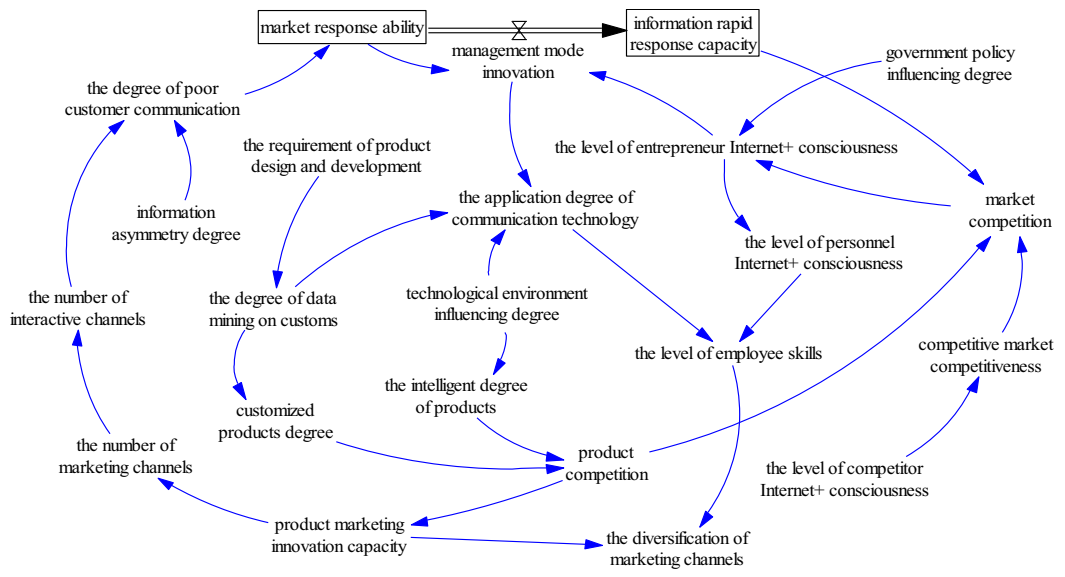

Fig.2. Stock and flow diagram of Internet+ impetus.

(1)Assume that the requirement of product design and development is 0.8 , and the competitor Internet + consciousness is 0.6 . 
(2)Assume that government policy influencing degree is $a_{1}$ and $a_{1}=0.40$, which is decided by the government concern degree and the development of enterprise Internet + , and it decreases with the improvement of Internet + .

(3)Assume that the promotion effect of technological environment is $b_{1}$ and $b_{1}=0.45$, which is decided by the maturity level and innovation level of technologies, and the more mature it is, the more obvious the impetus effect.

(4)Assume that information asymmetry is $c_{1}$ and $c_{1}=0.35$, which is determined by the information delivery speed and accuracy. It decrease with the improvement of information delivery speed and accuracy.

\section{Simulation and analysis on Internet+ impetus model}

When parameters of enterprise Internet+ impetus model are set, Vensim PLE is used to simulate the model. As Internet+ aims to solve the information asymmetry problem, improve the enterprise's ability to respond to information, and thus improve the ability of information processing. Therefore, government policy influencing degree, information asymmetry degree, technological environment are taken as the main factors to discuss their effect on enterprise Internet + impetus.

The simulation results of the model is shown in Figure 3. Here, Curve 4 shows the simulation result of set parameters in Section 3.2. Curve 3 shows the simulation result when government policy influencing degree increases from 0.4 to 0.7 . Curve 2 shows the simulation result when technological environment influencing degree increases from 0.45 to 0.75 . Curve 1 shows the simulation result when information asymmetry degree increases from 0.35 to 0.7 .

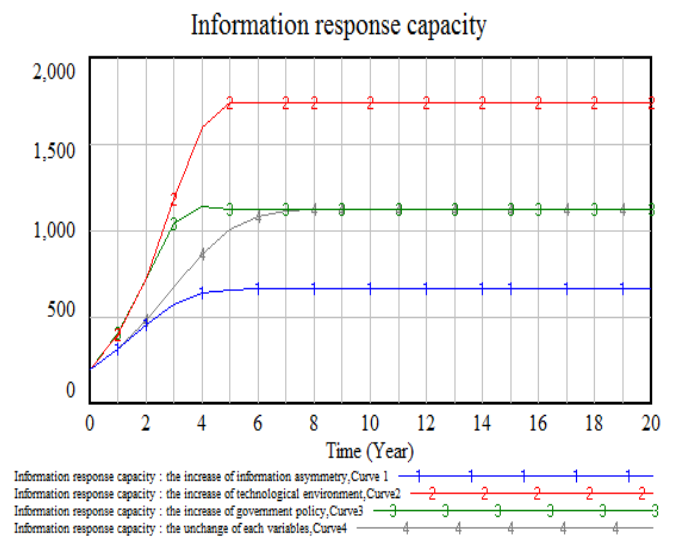

Fig.3. Different factor effect on enterprise Internet+ impetus.

From Figure 3, the following conclusions can be obtained:

(1) All curves are S - shaped curve. The slope is first increased and then decreased, and the overall trend is upward. Curve 2 reaches the maximum value when the saturation is reached, the maximum value of curve 1 is the smallest, the maximum value of curve 3 and the curve 4 are equal. The decrease order of the curves at saturation state follows: curve 2 , curve 3 , curve 4 and curve 1 .

(2) Curve 3 shows that with the increase of government policy, the speed of information response capacity increases. In comparison with the curve 4 , the shape of the curve is more steep, the time of reaching saturation is much earlier, and the saturation value of the two curves is same. It shows that government policy on information rapid response capacity is positive feedback, and increase in the government policy degree can enhance the ability to response to information, thus enhance enterprise Internet+ impetus.

(3) Curve 2 shows that with the increase of technological environment, the speed of information response capacity increases. Compared with curve 4 , the shape of curve 2 is more steep, reaching the saturation state earlier. It shows that the increase of technological environment influence can increase the information response ability and can make it reach saturation earlier. 
(4) Curve 1 shows that information asymmetry also influences information response ability. In comparison with curve 4 , curve 1 reached saturation state earlier, and the saturation value of curve 1 is less than that of curve 4 . It shows that the increase in information asymmetry degree can shorten the time to saturation but has less impact on the information response capacity.

\section{Suggestions for decision makers}

Factor analysis obtains the boundary of enterprise Internet+ impetus, and causal diagram and flow diagram realize qualitative and quantitative study of enterprise Internet+ impetus. According to the factor analysis of enterprise Internet + impetus, we have a further understanding on enterprise Internet + mechanism, thus the following strategies can be utilized to promote the impetus of enterprise Internet+:

(1)Government policies. In addition to the policies to promote enterprise Internet + implementation, government can establish industrial parks and incubators, so as to format industrial belt, find potential enterprise, and promote the implementing of Internet + . At the same time, government can introduce new technologies, provide professional guidance to enterprises, and help enterprises to cultivate professional employees. Government can also be a matchmaker, and realize the enterprise integration and cooperation between enterprises and internet enterprise resources.

(2)Technological environment. Enterprises should grasp the technical environment provided by information and communication technologies. For product research and development (R\&D) level, it is necessary to realize enterprise management mode reform to support personalized products. Enterprise should take strategies to improve their product design and R\&D, so as to realize the customized products. That is the way to enterprise Internet+.

(3)Ways to solve information asymmetry. Information asymmetry can be reduced by the reform of management mode in enterprises, and the expansion of interactive channels which can reduce the interaction between enterprise and customer. Therefore, enterprises can reform their organization structure as flat one so as to adapt to the new Internet+ ecological system.

\section{Conclusion}

Internet + has become an inevitable topic of this era, and enterprises are eager to implement it so as to increase their competition capacity. This paper discusses internal and external factors influencing the impetus of enterprise Internet + through system dynamics. A model of enterprise Internet+ impetus is established, and simulated by Vensim PLE. The impact of government policy, technological environment and information asymmetry has been discussed in detail. According to the simulation results, we can obtain that government policy and technological environment degree play crucial roles in the process of enterprise Internet+. And information asymmetry can also influence enterprise Internet+ impetus, but its influence is more obvious at the beginning. This study is helpful for enterprise and government to make decisions on the key factors when implementing Internet+.

\section{Acknowledgement}

This work is supported by National Natural Science Foundation of China Grant No. \#71371173, \#70971119. Academic Technology Leaders of the Provincial Education Department of Henan Project under Grant number 2014GGJS-103. Technology Innovation Talent plan of the Provincial Education Department of Henan under Grant number 16HASTIT037.

\section{References}

1. http://www.gov.cn/zhengce/content/2015-07/04/content_10002.html.

2. Z Zhao. Crossover administration of internet plus: perspective of creative destruction. CIE. 10(2015).

3. J J Ning. Background, connotation and content of Internet plus plan implementation. E-government. 06(2015). 
4. W Y You. "Internet plus"--driving the transformation and up grading of traditional industries. Statistical Theory and Practice,07( 2015).

5. H B Sun, Q L Guo, S G Pan etc. Energy Internet: concept, architecture and frontier outlook. Automation of Electric Power Systems, 39(2015).

6. M Xia, T Li etc. Closed-loop design evolution of engineering system using condition monitoring through internet of things and cloud computing. Computer Networks, 101(2016).

7. L Q Zhao and J Y Liu. Research on the Internet+ construction of railway engineering project material information system. Journal of Railway Engineering Society, 03(2016).

8. H Y Ren, S B Cheng and L C Huang. The strategy of emerging technology industrialization based on system dynamics. SRM. 34(2013).

9. J H Liu, X J Qian and M Li. Study on the dynamic factors of technology innovation of software industry based on system dynamics. Journal of Changzhou University (SOCIAL SCIENCE EDITION),04(2015).

10. $\mathrm{S}$ Oh, H Baek and $\mathrm{S}$ Lee. Research on the relationship between information technology capabilities and sustainable competitive advantages of enterprises. International Journal of Plant Engineering and Management, $\mathbf{0 3}(2012)$. 